\title{
Whatever You Do .... Don't Put the Computer Room Near the Maths Department! or, I Was an Early Adopter, an Enthusiastic Disseminator, But Now ...
}

\author{
David Demant \\ Museum Victoria, Melbourne, Australia \\ ddemant@museum.vic.gov.au
}

\begin{abstract}
This chapter contains accounts, descriptions and personal experiences in secondary schools in England, Canada and Australia, from the 1970 s to the 1980s; a period which saw the widespread introduction of computers into schools. The chapter ends with stories from another educational institution. What I learnt:

- Think not what a computer can do for you; think what you can or cannot do with a computer

- Look for the best way to solve a problem; it might not involve a computer

- Learning always takes place in all situations, good bad and in-between $[1]^{1}$, but for socially empowering outcomes:

○ there must be mutual respect between the participants, and

○ learners must have a measure of control over their learning.
\end{abstract}

Themes highlighted in this essay:

1. How computers did or did not change education

2. Teacher, parent and student expectations, concerns and visions

3. Use of computers 'across the curriculum'.

Keywords: computer, education, learning, empowerment, cut and paste, gender, professional development, cyber phobia, simulations.

\section{I Fell In Love ...}

... with computing, when the first desktop machines were introduced. I played with spreadsheets, databases, controlling physics experiments, desktop publishing and word processing; I played!

\footnotetext{
The 'secret' curriculum

"The teacher who cannot speak to grief, who will not laugh and cannot weep, teaches many very deep and memorable lessons about tears, laughter, grief and shame. The secret curriculum is the teacher's own lived values and convictions written in the lineaments of his expression and in the biography of passions or self-exile written in his eyes. The teacher who appears to his children to be anaesthetized, sedated in the face of human pain may not teach them anything at all about medical racism, birth mortality, of My Lai. But he will teach them a great deal about the capability of an average adult to abdicate the consequences of his own perception and, as it were, to vacate his own soul."
} 


\section{2 'Saul on the Road to Damascus'}

My teaching life was a succession of infatuations - chemistry, photography, physics, science for the 'less able', school drama productions, electronics and computing.

I am a project person; I like change; routine makes me careless, there is no adrenaline to put that extra mile in. In the early 1980s, I was ready for another challenge. It came labelled with the number 64.

In 1983, I bought a Commodore 64 and spent that night programming a game of table tennis . . . but I secretly agreed with my partner's question: "why bother?"

My whole mood changed when I checked out the word processor program . . .

Liberation!

I could move text around, have headings, correct mistakes and . . . cut and paste! Word processing just automated what I had been doing - writing essays and worksheets on hundreds of separate pieces of paper, which I then cut and pasted.

Then came VisiCalc - unbelievable, mind-blowing!

But I can't remember the name of the word processing software.

\section{Prologue}

As a school kid, I had a major logistical problem with writing essays; I liked (still do) to produce a stream of words in no particular order, so I could get all my ideas down before I forgot them. I would then restructure the essay in a most time-consuming way by literally cutting and pasting. The tedium was increased when I was at university, having to write longer (and longer) reports and essays.

I would write paragraphs with spaces in between. Each paragraph would have a heading and, sometimes, two or three sub-titles. I would physically separate each paragraph with a pair of scissors, and arrange them in a more logical order. The process might be repeated two or three times. Finally, I wrote the essay in full.

I followed the same process when I was a teacher producing student worksheets. When I was satisfied, I would Roneo or Gestetner them or use carbon paper. My hand writing started beautifully but soon slanted, became smaller and illegible. I was rarely satisfied, often screwing up the stencils and starting again.

One day, I used my dad's typewriter. A doctor fed up with complaints about his handwriting, he had bought the machine. With it, I could produce consistently neat and legible paragraphs, and they were more interesting visually. One problem, whiteout on the stencils never looked good.

Then came the photocopier; an improvement but with social problems at least in my school; only one person could operate the photocopier; he was a gatekeeper with many padlocks. You had to book weeks in advance; crawling was the only way to have your work ready on time.

On a one-year exchange in a Canadian school, I glimpsed the power of the Universal Machine. The physics teacher used four Commodore PETs and eight slide projectors to do a pictorial collage of the year at Christmas time. It was a little intimidating; he and a small group of students controlled the code and were too involved to explain it to the uninitiated. 
Back home, I bought a Sinclair ZX81. It took an hour to load a game, which, at the last micro second, crashed. I never played that game. I felt left out, and not for the last time.

Then came the Commodore $64 \ldots$

\section{$4 \quad$ Teaching the Teachers}

As a teacher, I developed computer skills by myself and through various courses. I applied for a week's long professional development on setting up a computer department. I had the approval of the School Council; the Principal was very enthusiastic. There was an entry requirement: the Education Department would only allow a minimum of two teachers from a school, and one had to be female.

Only males on the staff were interested. At a staff meeting, the principal appealed for someone to join me: total silence. Then, suddenly, as if by magic, we all saw that a hand had been raised, and its owner was female: "the school needs a computer department; it's the coming thing - I'll go but it's not my thing'. It never was, but I owe her.

I returned all fired up

With a good budget to support my efforts, I decided that the school needed a computer room as far away from the Mathematics and Physics departments as possible. Too many people were turned off by what they saw as unknown territory, one with fearful consequences, such as loss of control to machines.

I wanted the computer room at the very centre of the school, physically and culturally. I wanted it neutral. A sympathetic teacher gave me her room even though she did not like computers, and, previously, she had fought very hard for that room. It was perfect, opposite the main entry point for students. It had a small work room, which I used workshop cum store room. I obtained a number of Apple II Computers, disk drives, a couple of printers and a Mac. It was to be a place where the technically illiterate and fearful would feel welcome.

The school caretaker, a retired engineer, and I designed and produced mobile workstations, which could be used all over the school. They were designed to make it as easy as possible for people to use programs without any unnecessary preambles.
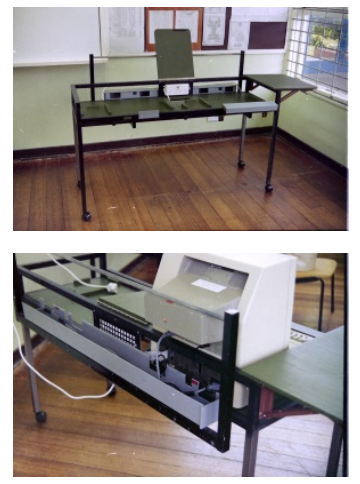
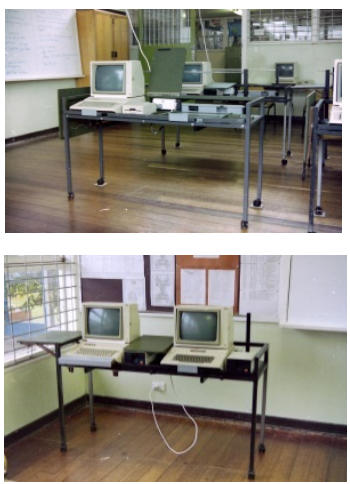
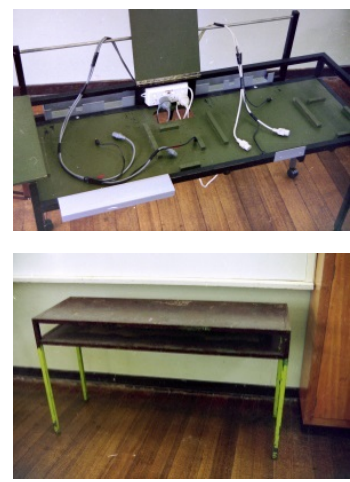

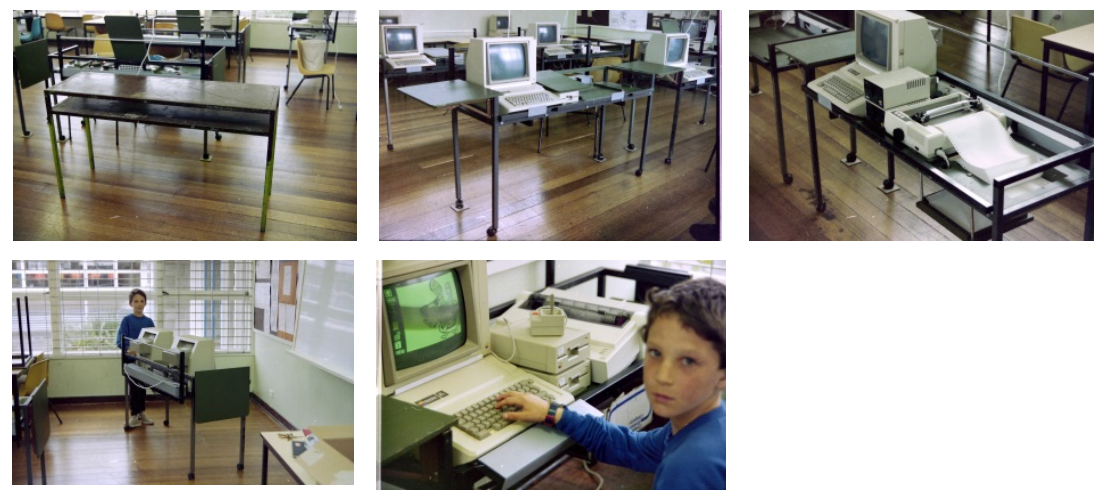

There were two spheres of activity in the computer department, training the teachers and running courses for the students. The first was much more difficult. Most teachers were very reluctant to adopt the new technology and a few could be described as 'cyber phobic'. One teacher was so fearful that he thought my choice of a different power socket, from the one used the previous week, was due to some evil desire on my part to dominate!

The teachers relied on me to assist them in the classes; the principal gave me time to do this. I ran classes in the use of applications, such as publishing, spreadsheets and word processing; the students and teachers had to collect the data themselves.

A history teacher took his class to the local cemetery and collected data from the gravestones - name, sex, date of birth and date of death. The data was entered into a spreadsheet. At first the searches were disappointing - how many were female, eighty years old and so on. The teacher felt it was not worthwhile, leading to no new historical understanding. I agreed with him secretly, but I knew this was a critical moment. If I could convince him of the value of computers for the development of historical understanding, then the other staff would be more receptive. One of the students noticed that there were a lot of deaths at an early age and at ages above 60; there were very few in the age range between. Analysis of the early deaths showed that many of them occurred in the 1920s. "The flu!" exclaimed the teacher; and the lesson developed from there. The teacher did not really take up computers independently, but others were inspired by this episode and similar ones.

Whatever a particular teacher's view, the students were mostly enthusiastic. The boys tended to want to play games while the girls were more interested generally in the word-processing and publishing software. I organised the lessons so the girls controlled access to the software and the hardware. This was accepted by most of the boys and it seemed that the girls gained much self-esteem through this. I organised a break-time club on the same basis. All went well until a group of teachers organised a girls' only computer club. One girl told me that she was sorry to leave my club but the girls felt obliged to join the other club. I soon had to pack up my club; all most boys wanted to do was to play games - the moderating influence of the girls was gone. 


\section{$5 \quad$ A Job at the Museum}

In 1987, I joined Museum Victoria. Museums are not like schools. Museums are door openers; the best take-away message from a museum is "I must find out more ..."

I became involved in developing exhibitions and programmes for general visitors and for teachers. In one exhibition about energy

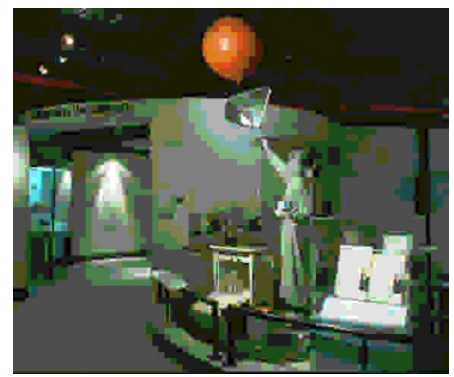

Climate modelling display sponsored by the CSIRO and Bureau of Meteorology

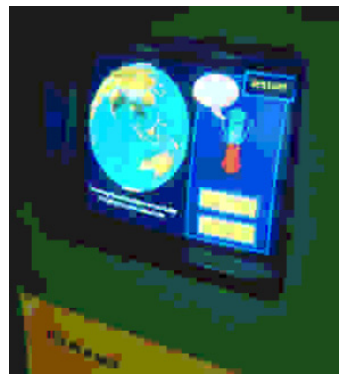

Touch screen interactive for modelling the Earth's climate at Scienceworks, there was a section devoted to computer modelling of the climate.

Other Scienceworks programmes included an educational package in which $\mathrm{VCE}^{2}$ students gathered data about the old sewage pumping station. Back at school, they used appropriate software to present narratives or reports.

\section{6 'The First Computer Mouse'}

This book was part of a package of products designed to complement an exhibition on digital technology at the new Melbourne Museum, when it opened in 2000. The exhibition highlighted the history of digital technology; pride of place was given to CSIRAC - the first computer built in Australia, the fourth in the world, and the only intact first generation computer in existence. CSIRAC is an abbreviation for Commonwealth Scientific and Industrial Research Organisation Automatic Computer.

The book tells two stories in parallel: one about the humans who operate CSIRAC and one about super-technological mice [2].

'The first computer mouse' was aimed at 8 to 12 year old children and their adult carers. Illustrations and minimum text were designed to ensure that there was a clear distinction between fact and fantasy.

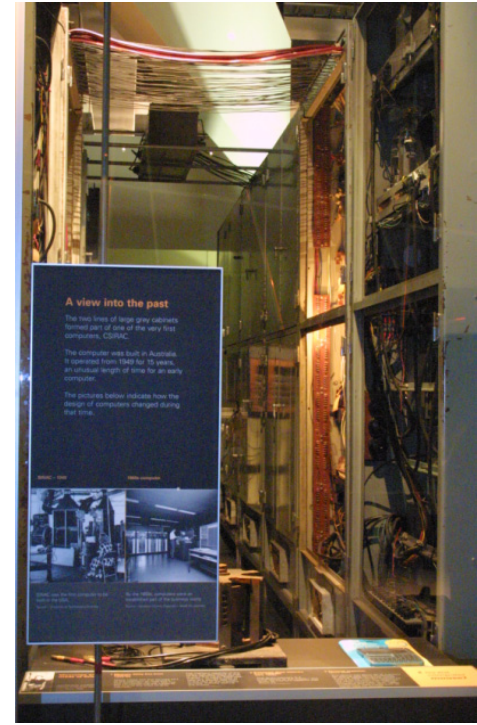

CSIRAC is currently on display in another area of Melbourne Museum

2 Victorian Certificate of Education. 


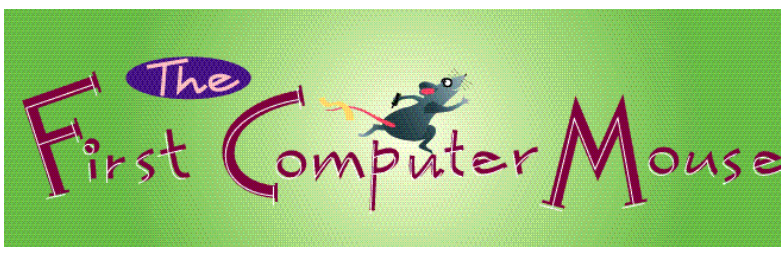

Illustrated by Deborah Koolen
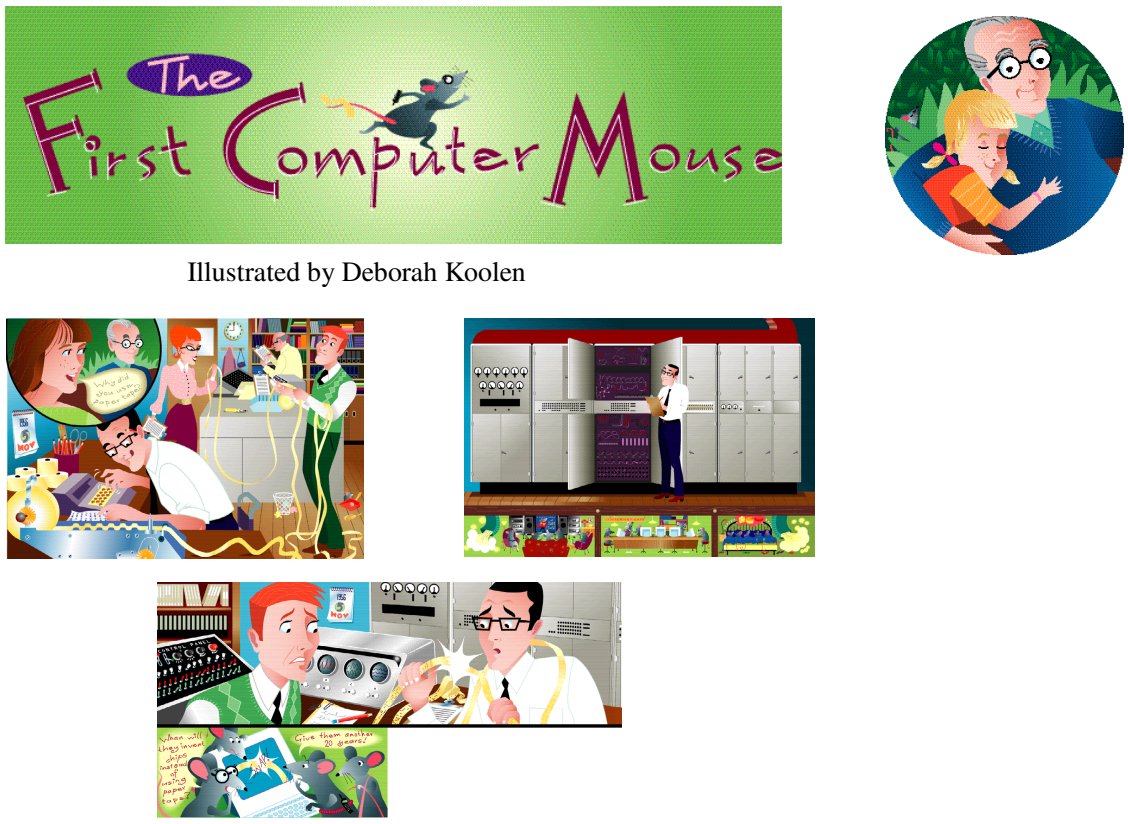

"Anna, Dan and Lucy are delighted when Grandad reminisces about the old computer he worked on when he was young. But more was happening than even Grandad realised. Under the floor was another world, whose inhabitants kept a careful watch on the humans and their computer. . . “

The take-away message of the book is that all computers, from the first to the latest, whatever their size or age, have essentially the same basic design: processor, memory, input and output. 'The first computer mouse' focuses the paper tape used as input and output, comparing it to their modern equivalents.

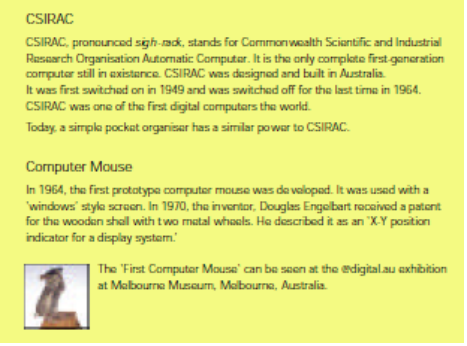

Note: the exhibition has been de-installed

\section{$7 \quad$ You Don't Necessarily Need a Computer to Explain Digital Technology}

An activity, called the Network Game, was another part of the package to support the digital technology exhibition. Simulating the net, it is best played with about hundred people. At the very beginning, the participants are told: "you are the Internet!" 


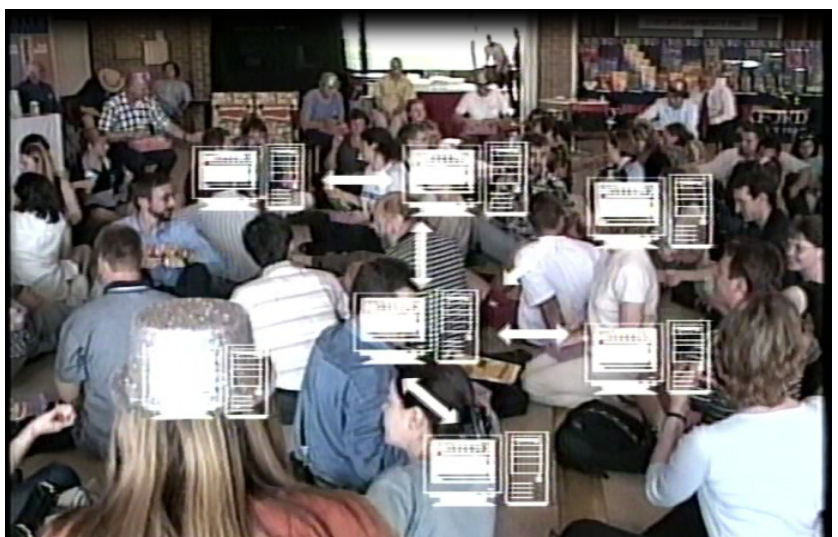

Participants in the programme, which was run close to the exhibition, ranged from upper primary students to teachers.

The game is compered by a presenter and the following description is a heavily edited version of the script used by the presenter.

The internet consists of millions of computers connected together

\subsection{Introduction}

The internet is basically made up of three types of computer. First is a client computer, for example your home computer. A client sends or receives messages to and from the second type - a server. Servers store the websites you want to access. Network computers (or routers) control the transport of messages between servers.

\subsection{Building the 'Human' Internet}

In a large space, a circle of six people (clients) sit on chairs forming a large circle. Each person wears a hat, labelled with a letter, A, B . . o or F.
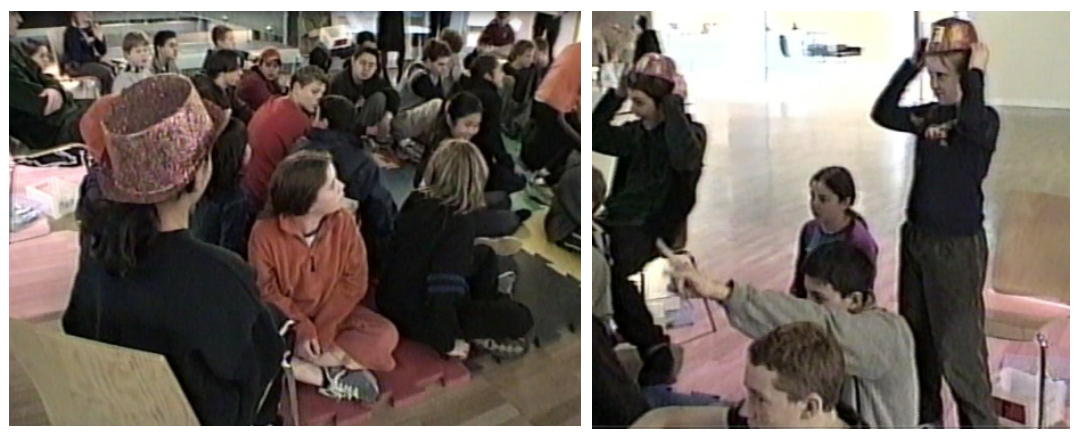

Clients wear hats

Another six people (servers) sit on the floor next to each client on the inside of the circle. The rest of people are routers and sit on the floor. One router (blue circle) sits in the centre of the circle of people on chairs (clients: A, B, C, D, E, F). One server sits next to each one of the clients (A, B, C, D, E, F) inside the circle. Three routers sit 
around each of these servers. Four routers (black circles) sit evenly spaced at arm's length around the centre router. Three more routers (red circles) sit around each one of these four central routers.
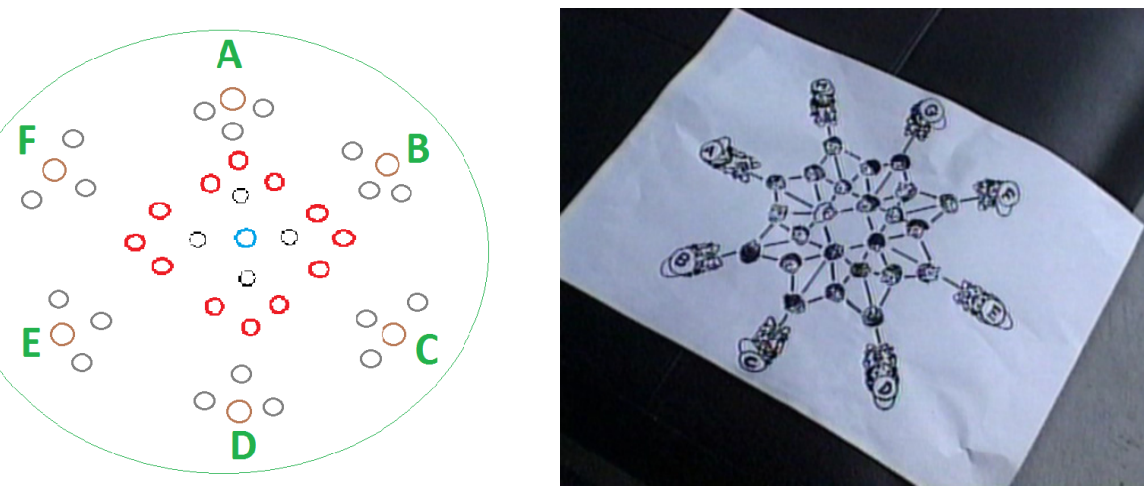

... each of the red routers is surrounded by three more routers . . . this goes on until there is no one left.

\subsection{Background to the Game}

The Internet carries an enormous volume of traffic and it is designed to deliver messages as efficiently and as fast as possible. Traffic jams are avoided by breaking messages into small packets so that each packet makes its own way to the destination server, choosing the least congested route.

\subsection{Ping Pong Balls for Packets}

Labelled ping pong balls can be used as packets; each labelled with a destination either A, B, C, D, E or F. Each client is given a box with lots of labelled ping pong balls (packets) ${ }^{3}$.

\subsection{The Rules}

Clients give packets, one by one, to the nearest server. Servers pass packets, one at a time, to the nearest router. Routers pass one packet at a time to the closest available router. Packets can only be passed on if the other router can accept them. Routers can temporarily store packets in little baskets, but not if the basket is full. If they are full, no more packets can be accepted until one or more of the stored ones are passed on. A packet then tries another path. When the packets get to their destination, the clients store them in boxes.

3 An extended version of the game involves the writing of messages, which are translated into digital code and labeled - see later in this chapter. Each packet is identified with symbols or numbers representing the sender, receiver, message ID, and position of packet in the message. The packets are then folded and used in the game instead of ping pong balls. 


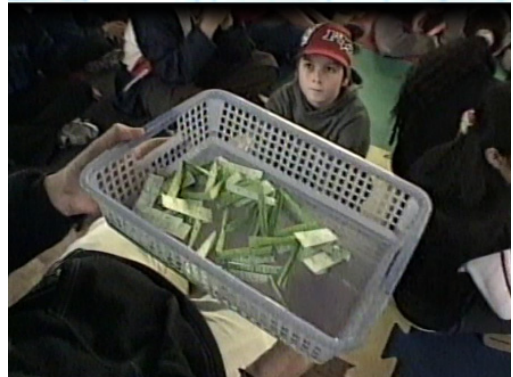

Packets stored temporarily in a router's memory
Packets can travel back as well as forwards - by any available path - it does not matter.

It does not matter which path the messages take. If you send a message to Sydney, some of the packets might go via Beijing, others via Paris, others via Buenos Aires, but they are all arrive at the same place.

\subsection{The Game Is Played ...}

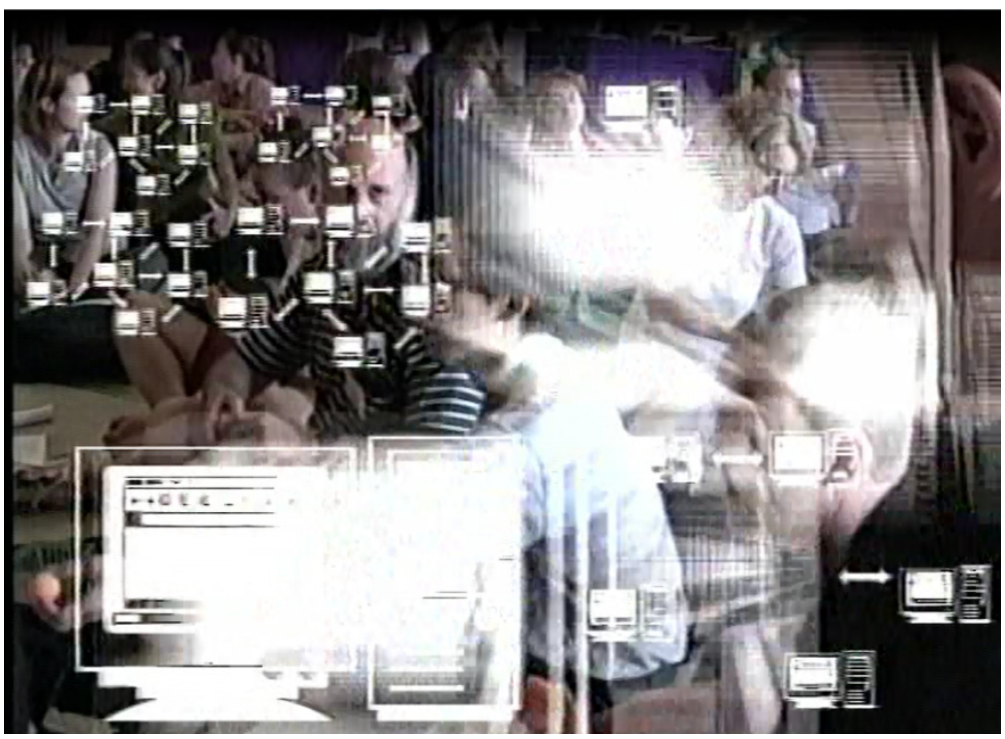

Humans simulating the net

\subsection{Simulations}

Once the participants have the general idea, some real life simulations can be tried.

- A cluster of 3 routers can stop passing packets to simulate sabotage or server crash. The network will still get the packets to their destinations using other routers.

- If a client fails, the packets destined for it have to be kept circulating or be stored until the client is operating again.

- If the destination mark is not clear, then the packet is condemned to circle the internet forever or until a router leaves it in its store or deletes it (i.e. chucks it on the floor). 


\subsection{Extension of the Game}

An extended version of the game involves the writing of messages, translating into digital code on a grid drawn on a sheet of paper, cutting the paper grid into separate sections and constructing paper packets.
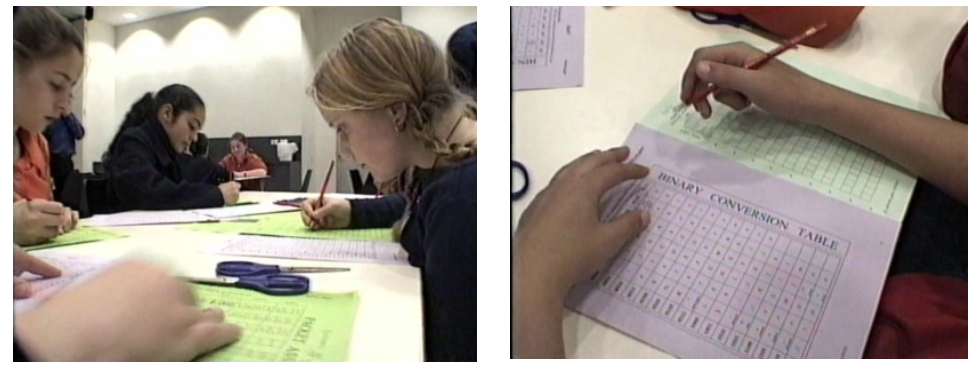

Coding the message on a grid

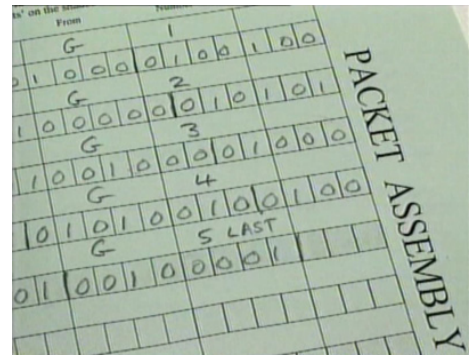

Labelling the packets

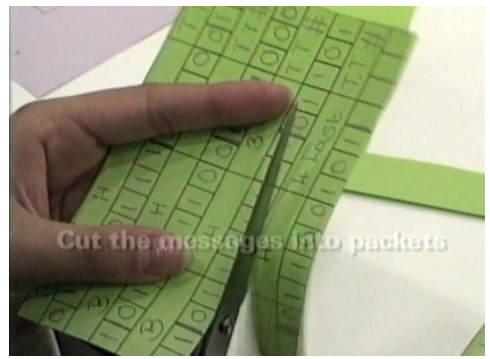

Cutting out the packets

Each packet is identified with symbols or numbers representing the sender, receiver, message ID, and position of packet in the message. The packets are then folded and used in the game instead of ping pong balls. After the game, the messages are reassembled from the pile of packets, and decoded.

\section{I was an Early Adopter, an Enthusiastic Disseminator, but Now ...}

I get tired of accessing websites that are designed to trap you or are just badly designed, but I like Google and Google translation. My resistance to Facebook is still high but less to LinkedIn. One day I received 25 emails from Facebook, each informing that a friend (a real one) had added another image. On one occasion, however, Facebook gave me a pleasant surprise: a pen friend, who I last saw in 1958, contacted me. The other day, I started learning how to use Microsoft Access 
to document my family history and I began to reach out to others using its web facility ... and my brother's daughter in England put a lovely picture of her daughter on Facebook...

\section{References}

1. Kojol, J.: The Open School Room. Quarterly Book List, 1972 (Spring 1972)

2. Demant, D.: The First Computer Mouse. Museum Victoria Publications, Melbourne (2001) 